\title{
Prevalence and risk factors of bovine schistosomiasis in Northwestern Ethiopia
}

\author{
Abebe Yihunie ${ }^{1}$, Befikadu Urga ${ }^{1}$ and Getachew Alebie ${ }^{2^{*}}$ (D)
}

\begin{abstract}
Background: Parasitic diseases remain major bottle neck to livestock development in developing nations. The objective of this study was to determine the prevalence and associated risk factors of Bovine Schistosomiasis (BS) in South Achefer District, northwestern Ethiopia.

Methods: A cross-sectional copro-parasitological and observational study was conducted in South Achefer district from October, 2015 to April, 2016. Faecal samples were collected from 360 randomly selected cattle for coprological examination of Schistosoma eggs using sedimentation technique. The geographical origin (kebele), signalment (breed, sex and age) and body condition of study animals were recorded as independent variables.

Results: Of the total of 360 faecal samples examined, 80 (22.2\%) were found positive for Schistosoma bovis eggs. Prevalence of BS showed significant variability amongst study kebele's ( $p=0.000$ ) as well as between different breeds $(p=0.009)$, sexes $(p=0.030)$ and body condition groups $(p=0.000)$ of study animals. Compared to Gedema kebele, risk of Schistosomia bovis infection was significantly higher $(p<0.05)$ in Ahurie kebele $(95 \% \mathrm{ClOR}, 1.497-6.680)$ and lower in Kar kebele (95\% Cl OR, 0.069-0.507). Meanwhile, risk of BS was significantly higher in cattle with poor body condition (95\% Cl OR, 3.171-15.652) as compared to that exhibiting good body condition. Local breed (95\% Cl OR, $1.282-5.102)$ and female $(95 \% \mathrm{Cl} \mathrm{OR}, 1.018-3.634)$ cattle showed considerably higher risk of infection than crossbred and male cattle, respectively.
\end{abstract}

Conclusion: Overall, agro-ecological, genotypic and sexual factors were important in determining prevalence of BS which had negative association with the nutritional status of cattle. Current and parallel prior observations underscore a need for careful consideration of the disease and its epidemiological drivers in genetic improvement programs and routine health management practices.

Keywords: Prevalence, Risk factors, Bovine schistosomiasis, South Achefer, Ethiopia

\section{Background}

Schistosomiasis caused by trematodes of the genus Schistosoma, is an economically and medically important parasitic disease of man and animals [1]. The disease is responsible for considerable economic losses in livestock industry, mainly through mortality, reduced fertility and productivity, stunted growth [1-3].

The major schistosome species of veterinary importance include Schistosoma bovis, S. mattheei, S. intercalatum, S. spindale, S. nasalis, S. indicum, S. hippopotami and S. rohhaini $[2,4]$. Snails belonging to Bulinus and Physopsis genera, serve as intermediate hosts of bovine schistosomes,

\footnotetext{
* Correspondence: gechalebie@gmail.com

${ }^{2}$ Department of Biology, Jigjiga University, P.O. Box- 1020, Jijiga, Ethiopia

Full list of author information is available at the end of the article
}

potentially determining distribution of BS in different parts of the world [5]. S. bovis is the commonest species in Africa and Mediterranean Europe [6] whereas S. spindale, S. indicum and S. nasalis were reported as major cause of BS in Asia [4]. Infestation with bovine schistosome parasites is usually associated with grazing in wet land and drinking from the snail infested watering places [7].

In Ethiopia, S. bovis is known to be the main cause of BS which is recognized as an important bottleneck to livestock development. The disease is focally distributed in northern, eastern, south western and central parts of the nation [8]. Available evidences reveal that its prevalence in the country ranges from 1.5 to $37.3 \%$ [9-16]. This study aimed to estimate the prevalence of BS and identify associated risk factors in north western Ethiopia.

(c) The Author(s). 2019 Open Access This article is distributed under the terms of the Creative Commons Attribution 4.0 International License (http://creativecommons.org/licenses/by/4.0/), which permits unrestricted use, distribution, and 


\section{Methods}

\section{Study area}

The study was conducted in South Achefer district, North-western Ethiopia. The district is one of the thirteen districts found in West Gojjam Administrative Zone located $60 \mathrm{~km}$ south-west of Bahir Dar town, the capital city of Amhara Regional State. According to the district agricultural office sources, the total geographical area of South Achefer district is about 118,228 ha. The total human population of the district is about 148,974; of which 134,447 or $90.2 \%$ live in rural areas and 14,528 or $9.8 \%$ of the population is urban resident [17]. The estimated livestock population of the district is 53,612 cattle, 80,868 sheep and goats, 22,375 equines, 16,721 bee colonies, 74,689 poultry and 16,684 other domestic animals [18]. South Achefer district is located at latitude of $11^{\circ} 2132^{\prime \prime} \mathrm{N}$ and longitude of $36^{\circ} 57^{\prime} 42^{\prime \prime} \mathrm{E}$. Altitudes in the district range from 1500 to $2500 \mathrm{~m}$ above mean sea level. The mean annual rain fall ranges from 1450 to $1594 \mathrm{~mm}$ with average annual temperature of $26.8^{\circ} \mathrm{C}$.

According to the Amhara Design and Supervision Works Enterprise (ADSWE) Animal Health Assessment report in different districts along Tana-basin, liver fluke (Fascioliasis) and schistosomiasis were ranked as top two livestock health problems in South Achefer district in terms of their severity, economic importance and incidence [19]. The report revealed these diseases to be very series problem in permanent wet-lands of the district causing poor weight gain, death, poor milk yield, poor feed conversion and poor reproductive capacity.

\section{Study design}

A cross-sectional copro-parasitological and observational study was conducted to assess the prevalence and associated risk factors of BS in South Achefer district between October 2015 and April 2016. All cattle (53,612 heads) of different breeds, sex and age groups in the district were enrolled in the study. Two-stage semi-random sampling was applied for selecting cattle for the field survey. In the first stage, study kebeles (Ahirie, Afrefida, Kar and Gedema) were selected based on practical logistic and demographic considerations. In the second stage, every 5th farm household encountered during field survey was systematically selected and then cattle were randomly selected for the study.

\section{Sample size determination}

Sample size (n) was determined according to Thrusfield [20], with 95\% confidence level $(z=1.96), 5 \%$ desired absolute precision (d) and $24.3 \%$ expected prevalence (pexp) [11].

$$
\text { i.e. } n=\frac{z^{2} \exp (1-p \exp )}{d^{2}}
$$

This gave a sample size of 283 heads of cattle. To generate reliable data outputs and to increase the precision, the sample size was increased to 360 heads of cattle.

\section{Observation}

The geographical origin (kebele), signalment (breed, sex and age) and body condition of study animals were noted through visual inspection and owner's interview. Breed of cattle was categorized as local (Fogera breed) or cross-bred (Local - Holstein Friesian). Age of the cattle was categorized following the methods of Pope [21], and Ferguson [22] respectively whereas body condition was subjectively rated as good (no visible bony prominences i.e. rib cage and tail base), medium (outline of bony prominences visible) or poor (grossly prominent bony prominences) based on visual assessment.

\section{Coprological examination}

Fresh faecal samples were directly collected from the rectum of cattle in the field using gloved hand. The collected sample was preserved in $10 \%$ formalin in clean and labelled screw cap universal bottle to prevent hatching of miracidia before reaching laboratory to diagnose within $24 \mathrm{~h}$ of collection. It was placed in ice box and transported to Durbete veterinary clinic parasitology laboratory. Then, the samples were concentrated using standard sedimentation technique described by Hansen and Perry [23]. Briefly, about $3 \mathrm{~g}$ of faeces were taken in to centrifuge tube and $40 \mathrm{ml}$ of water was added and then mixed thoroughly. The suspension was filtered through a tea strainer into other centrifuge tube and was left for 15 min. Thereafter, the supernatant was decanted and the sediment was re-suspended. This step was repeated 3 times until the supernatant was cleared. Finally, the sediment was transferred with a pipette to a clean slide and observed under low power (10x) microscope. The slides were judged positive when oval to spindle shaped with centrally bulged and terminal spine on one side of egg was identified.

\section{Data analysis}

Data was entered into Microsoft Excel spread sheets and analysed using SPSS statistical software version 16. Descriptive statistics were computed to determine frequency and percentage. Chi-square test was used to analyse associations between independent variables (such as cattle origin, breed, sex, age group and body condition) and BS infection. Variables that independently showed significant association were entered in to a logistic regression model. The magnitude of association was measured using 95\% confidence interval Odds Ratio (B Exp). Logistic regression model 
assumptions were tested by changing significance of the Change in $-2 \log$ Likelihood at $p$-value of $<0.05$.

The study was reviewed and approved by College of Veterinary Medicine - Jigjiga University. Verbal informed consent was obtained from cattle owners to involve animals in the study. Thereafter, stool sample were collected with no harm caused on the cattle as per the research ethics of the college.

\section{Results}

Out of the total 360 faecal samples examined, 80 (22.2\%) were found to be positive for S.bovis eggs. Higher BS prevalence was recorded in Ahurie kebele followed by Afrefida kebele which constituted 40 and $26.7 \%$ respectively. The disease showed higher infection rate in local breed (25.9\%) than in cross breed (13.3\%). High infection rates was observed in females and in the age group 2-3 years with the prevalence of 25.6 and $26.4 \%$ respectively. The prevalence of BS was high (36.1\%) in cattle with poor condition (Table 1).

As depicted in Table 2, cattle origin followed by body condition were identified as major factors associated with prevalence of BS $(P=0.000)$. These were followed by the breed and sex of cattle $(P<0.05)$. Cattle in Ahurie kebele were 3.162 times more likely to be infected by BS than cattle in Gedema kebele whereas cattle in Kar kebele had 0.18 times less chance of acquiring BS infection. Cattle with poor body condition were 7.045 times more likely to harbour BS than cattle with good body condition. Female cattle were 1.923 times at high risk of BS infection than male cattle whereas local breed cattle were 2.558 times more likely to be infected by BS than cross breed cattle.

\section{Discussion}

Epidemiological studies on animal schistosomiasis that focus on identifying target population and epidemiological mechanisms including factors determining transmission and spread are key for designing appropriate disease control strategies in endemic areas. The prevalence of BS in the current study was lower than previous reports from the same district [15]. This may be attributed to the fact that only random lottery method selected local breed cattle were investigated in the latter study. Meanwhile, comparable $[11,13,16,24,25]$, lower $[8,10,24,26]$ and higher $[21,27] \mathrm{BS}$ prevalence rates were previously reported from different regions of the country. Corresponding trends may be attributed to study design, agro-ecological and husbandry related differences.

Infection rate of BS was significantly varied across different localities of the study district. This might be related to differences in topography and agro-ecological factors, such as temperature, moisture, humidity, availability of large permanent water bodies, and irrigation practices crucial to sustain schistosome life cycle. Proximity of cattle residence and grazing area to cercaria infested water bodies can be an important factor underlying observed prevalence variations. Hansen and Perry [23] reported that key determinant in the epidemiology of bovine schistosomiasis is the relative abundance of the intermediate hosts and their ability to develop and survive in the environment which is associated with large permanent water bodies. Marshy areas and stagnant water bodies like small streams, ponds, and swamps around rivers, lakes and irrigation sites represent major sources of infection for schistosomiasis [5].

Currently, BS affected local breed cattle more than cross-breeds. This trend was consistent with other studies

Table 1 The prevalence of Bovine Schistosomiasis based on cattle origin, breed, sex, age and body condition in the study area

\begin{tabular}{|c|c|c|c|c|c|}
\hline Variable & Catagory & Total examined & No. of positive (\%) & $x^{2}$ & $P$-value \\
\hline \multirow[t]{4}{*}{ Origin } & Ahurie & 90 & $36(40.0)$ & 32.4 & 0.000 \\
\hline & Afrefida & 90 & $24(26.7)$ & & \\
\hline & Kar & 90 & 14(15.6) & & \\
\hline & Gedema & 90 & $6(6.7)$ & & \\
\hline \multirow[t]{2}{*}{ Breed } & Local & 255 & $66(25.9)$ & 6.78 & 0.009 \\
\hline & Cross & 105 & 14(13.3) & & \\
\hline \multirow[t]{2}{*}{ Sex } & Male & 122 & 19(15.6) & 4.72 & 0.030 \\
\hline & Female & 238 & $61(25.6)$ & & \\
\hline \multirow[t]{3}{*}{ Age } & $<2$ & 98 & 18(18.4) & 2.22 & 0.329 \\
\hline & $2-5$ & 129 & $34(26.4)$ & & \\
\hline & $>5$ & 133 & $28(21.1)$ & & \\
\hline \multirow[t]{3}{*}{ Body condition } & Poor & 133 & $48(36.1)$ & 26.4 & 0.000 \\
\hline & Medium & 111 & $21(18.9)$ & & \\
\hline & Good & 116 & $11(9.5)$ & & \\
\hline
\end{tabular}


Table 2 Binary logistic regression model output for factors associated with infection rate of Bovine Schistosomiasis in the study area

\begin{tabular}{|c|c|c|c|c|c|c|c|c|}
\hline Variable & Catagory & Positive (\%) & B & $\operatorname{Exp}(B)$ & $95 \% \mathrm{Cl}$ & $P$-value & Change in -2 Log Likelihood & $P$-value \\
\hline \multirow[t]{4}{*}{ Origin } & Ahurie & $36(40.0)$ & 1.151 & 3.162 & $1.497-6.680$ & 0.003 & 46.128 & 0.000 \\
\hline & Afrefida & $24(26.7)$ & -0.365 & 0.694 & $0.308-1.566$ & 0.379 & & \\
\hline & Kar & 14(15.6) & -1.675 & 0.187 & $0.069-0.507$ & 0.001 & & \\
\hline & Gedema & $6(6.7)$ & & & & & & \\
\hline \multirow[t]{2}{*}{ Breed } & Local & $66(25.9)$ & 0.939 & 2.558 & $1.282-5.102$ & 0.008 & 7.904 & 0.005 \\
\hline & Cross & 14(13.3) & & & & & & \\
\hline \multirow[t]{2}{*}{ Sex } & Male & 19(15.6) & & & & & 4.281 & 0.039 \\
\hline & Female & $61(25.6)$ & 0.654 & 1.923 & $1.018-3.634$ & 0.044 & & \\
\hline \multirow[t]{3}{*}{ Body condition } & Poor & $48(36.1)$ & 1.952 & 7.045 & $3.171-15.652$ & 0.000 & 30.718 & 0.000 \\
\hline & Medium & 21(18.9) & 0.767 & 2.154 & $0.938-4.948$ & 0.070 & & \\
\hline & Good & $11(9.5)$ & & & & & & \\
\hline
\end{tabular}

$[13,28]$ but in conflict of other findings [14, 24, 25, 27]. Variations observed between Fogeral and Fogera Holstein Frisian crossbred cattle is most probably attributed to difference of husbandry conditions under which corresponding are maintained. Cross-bred dairy cattle are commonly kept under semi/ intensive management system which reduce risk of exposure to infected reservoir hosts. However, investigations are required to rule out potential genetic basis of predisposition to BS.

In agreement with current findings, some researchers had reported a higher prevalence of BS in female cattle compare to in male cattle $[13,24,28]$ whereas others noted a reverse trend $[10,29,30]$. In the present study area, female cattle commonly grazed in Schistosoma contaminated pastures and water points whereas male cattle spent most of their time on farm land ploughing activities which could be reducing risk of exposure to cercaria infested habitats. However, the role of sex hormone related immunological influences on differential disease susceptibility trends also demands further study. On the other hand, a higher prevalence of BS was noted in cattle exhibiting poor nutritional status. This is in agreement with findings reported by Merawe et al. [30] and Belayneh and Tadesse [11]. Urqhart et al. [5] and Hansen and Perry [23] had reported that bovine schistosomes utilized the hosts' nutrition and compromise its immune competence, both of which lead to pathologies, including anorexia, emaciation and disease predisposition. In this study, a relatively $(p>0.05)$ higher prevalence of BS was noted in adult cattle. A similar trend was also reported by Melkamu [31] in Bahir Dar and the surrounding areas. Lower risk of BS in younger animals could be attributed to husbandry differences which reduce risk of environmental exposures. On the other hand, old cattle may have developed stronger acquired immunity which suppresses worm fecundity and the release of parasitic eggs in faeces [32].

\section{Conclusion}

BS is a common disease problem of cattle in South Achefer district. Prevalence of BS showed significant variations across study kebele's, cattle breeds and sexes as well as a negative association with nutritional performance. Such variations emphasize critical relevance of considering agro-ecological conditions and husbandry practice related risk factors in disease prevention and control inventions. Potential genetic and physiological (sex hormone related) influences need to be ruled out through deeper investigation.

Abbreviations

BS: Bovine schistosomiasis; Cl: Confidence interval; OR: Odds ratio

Acknowledgements

Not applicable.

Funding

Not applicable.

Availability of data and materials

All data generated or analysed during this study are included in this published article.

Authors' contributions

AY is principal investigator. BU and GA worked as advisors and organized the paper. All authors read and approved the final manuscript.

Ethics approval and consent to participate

The study was reviewed and approved by College of Veterinary Medicine Jigjiga University. Verbal informed consent was obtained from cattle owners to involve animals in the study, and stool sample were collected with no harm caused on the cattle.

Consent for publication

Not applicable.

Competing interests

The authors declare that they have no competing interests.

\section{Publisher's Note}

Springer Nature remains neutral with regard to jurisdictional claims in published maps and institutional affiliations. 


\section{Author details}

${ }^{1}$ College of Veterinary Medicine, Jigjiga University, P.O.Box-1020, Jijiga, Ethiopia. ${ }^{2}$ Department of Biology, Jigjiga University, P.O. Box- 1020, Jijiga, Ethiopia.

Received: 28 May 2018 Accepted: 21 December 2018

Published online: 07 January 2019

\section{References}

1. Lefevre CP, Blancou J, Chermette R, Uilenberg G. Infectious disease of livestock. 1st ed. Paris: Lavoizer; 2010.

2. Okpala HO, Agwu E, Agba MI, Chimezie OR, Nwobu GO, Ohihoin AA. A survey of the Prevalence of schistosomiasis among pupils in Apata and Laranto areas in Jos, plateau state. Online J Health Allied Scs. 2004;1:1-4.

3. Pichford RJ, Visser PS. Schistosoma mattheei Veglia and LE roux, 1929, egg output from cattle in a highly endemic area in the eastern Transvaal. Onderstepoort J Vet Res. 1982;49:233-5.

4. Bont JD. Cattle Schistosomosis: host-parasitie interactions. PhD.Thesis in veterinary medicine. University of gent, 1995. http://hdl.handle.net/10568/ 79588. Accessed 25 Aug 2017.

5. Urquhart GM, Armour J, Duncan JL, Dunn AM, Jennings FW. Veterinary helminthology: Veterinary Parasitology. New York: Churchill: Livingstone Inc; 1996.

6. Shibru T, Getachew T, Hailu B. Parasitology. In: Shibru T, Getachew T, Kloos $\mathrm{H}$, editors. Schistosomosis in Ethiopia. Addis Ababa: Addis Ababa printing press: 1989. p. 18-26.

7. Payne WJA. An Introduction to Animal Husbandry in the Tropics. 4th ed. New York: Longman: Troical Agriculture series; 1990.

8. Yalelet W. Survey on bovine schistosomasis in and around Bahir Dar, north western Ethiopia. Glob Vet. 2004;3:12-5.

9. Lo C. Lemma a. a study on Schistosoma bovis. Anls. Trop Med Parasitol. 1973;69:375-82

10. Chanie M, Dejen B, Fentahun T. Prevalence of cattle schistosomiasis and associated risk factors in Fogera cattle. J Adv Vet Res. 2012;2:153-6.

11. Belayneh L, Tadesse G. Bovine schistosomiasis: a threat in public health perspective in Bahir Dar town, northwest, Ethiopia. Acta Parasitol Glob. 2014;5:1-6.

12. Almaz H, Solomon W. Repeated simple sedimentation technique and Prevalence of bovine schistosomiasis in selected sites of Bahir Dar woreda. Bahir Dar, Ethiopia Ethiop Vet J. 2011;15:49-57.

13. Gebru A, Asaye M, Alemneh T. The Prevalence of bovine Shistosomiasis in Dembia Woreda. Ethiopia Acta Parasitol Glob. 2015;6:112-6.

14. Tsega M, Derso S. Prevalence of bovine schistosomiasis and its associated risk factor in and around Debre Tabor town, north west of Ethiopia. Europ J Biol Sci. 2015;7:108-13.

15. Kerie Y, Seyoum Z. Bovine and ovine schistosomiasis: prevalence and associated host factors in selected sites of South Achefer district, Northwest Ethiopia. Thai J Vet Med. 2016:46(4):561-7.

16. Shiferaw MB, Deressa FB. Prevalence and Associated Risk Factors of Bovine Schistosomiasis in and Around Bakko Town, west Shoa Zone, Oromia, Ethiopia. Global J Sci Front Res. 2017; Volume (D) XVII: Issue ersion I. Online ISSN: 2249-4626 \& Print ISSN: 0975-5896.

17. ARSBFED. Amhara regional state bureau of finance and economic development. Population prediction, 2011. www.amharabofed.gov.et. Accessed 17 Aug 2016

18. Central Statistical Agency (CSA), 2008. Ethiopian Agricultural Sample Survey, 2007/8, Vol. II, Statistical report on Livestock and Livestock Characteristics, Addis Ababa 2008. https://searchworks.stanford.edu/view/7935383.

19. Amhara Design and Supervision Works Enterprise (ADSWE). 2014. In: Tana sub basin Land Use Planning and Environmental Study Project Technical Report Volume X: Animal Health Assessment. 2015, Bahirdar, Ethiopia. https://mahiderzewdie.files.wordpress.com. Accessed 11 Jul 2017.

20. Thrusfied M. Survey in veterinary epidemiology. 2nd ed. Cambridge: Blackwell science Ltd.; 2005.

21. Pope GM. Determining the age of cattle by their teeth. Farmers' Bulleitin1066 USA Departement of Agriculture. 2008:1-12.

22. Ferguson JD. Review of body condition scoring dairy herd 2011. https://www. txanc.org/docs/Body-Condition-Scoring.pdf. Accessed 23 Nov 2013.

23. Hansen J, Perry B. The epidemiology, diagnosis and control of helminth parasite of ruminants: a hand book of animal production and health division, FAO, Rome, Italy. Int Hlth. 1994;3:372.
24. Solomon A. Observation on the prevalence the prevalence of Schistosoma Bovis infection in Bahir Dar area. North Central Ethiopia. Glob Vet. 2008;3:13-6.

25. Aylate A, Hussen M, Tilahun A, Kiros A. A cross-sectional study on bovine schistosomiasis in and around Kemissie, Dawa Cheffa District. JVMAH. 2017;9:72-7.

26. Almaz $\mathrm{H}$, Tamiru $\mathrm{N}$, Asegedech $\mathrm{S}$, et al. Pathology of natural infections of Schistosoma bovis in cattle in Ethiopia, Bahir Dar, Ethiopia. Glob Vet. 2013;11:243-7.

27. Ameni G, Krok B, Bogale T. Preliminary study on the major bovine trematodeinfection around Kemissie, northeastern Ethiopia and treatment trial with praziquantel. Bull Anim Hlth Prod Afr. 2001:49:62-7.

28. Yeneneh A, Kebede H, Fentahun T, Chanie M. Prevalence of cattle flukes infection at Andassa livestock research center in north-west of Ethiopia. Veterinary Research Forum. 2012;3:85-9.

29. Setargew M, Fentahun T, Chanie M. Prevalence of bovine Shistosomiasis in Fogera District, South Gondar zone, Amhara National Regional State, Northwest Ethiopia. Glob Vet. 2012;9:612-6.

30. Merawe M, Amsslu K, Hagos Y, Afera B. Intestinal schistosomiasis of bovine and ovine in Fogera district, South Gondar zone, Amhara National Regional State, Ethiopia. Acta Parasitol Glob. 2014:5:87-90.

31. Melkamu S. Study on Prevalence and associated risk factors of bovine and human schistosomiasis in Bahir Dar and its surrounding areas. J Anim Res. 2016;6:967-75.

32. Bushara HO, Hassein MF, Majid AA, Taylor MG. Effective of praziquantel and metiozonat on schistosoma bovis. Am J Trop Med Hyg. 1982:442-5.

\section{Ready to submit your research? Choose BMC and benefit from:}

- fast, convenient online submission

- thorough peer review by experienced researchers in your field

- rapid publication on acceptance

- support for research data, including large and complex data types

- gold Open Access which fosters wider collaboration and increased citations

- maximum visibility for your research: over $100 \mathrm{M}$ website views per year

At BMC, research is always in progress.

Learn more biomedcentral.com/submissions 